\title{
HOMENAJE AL CATEDRÁTICO PROF. DR. D. JUAN MIGUEL GONZÁLEZ GÓMEZ
}




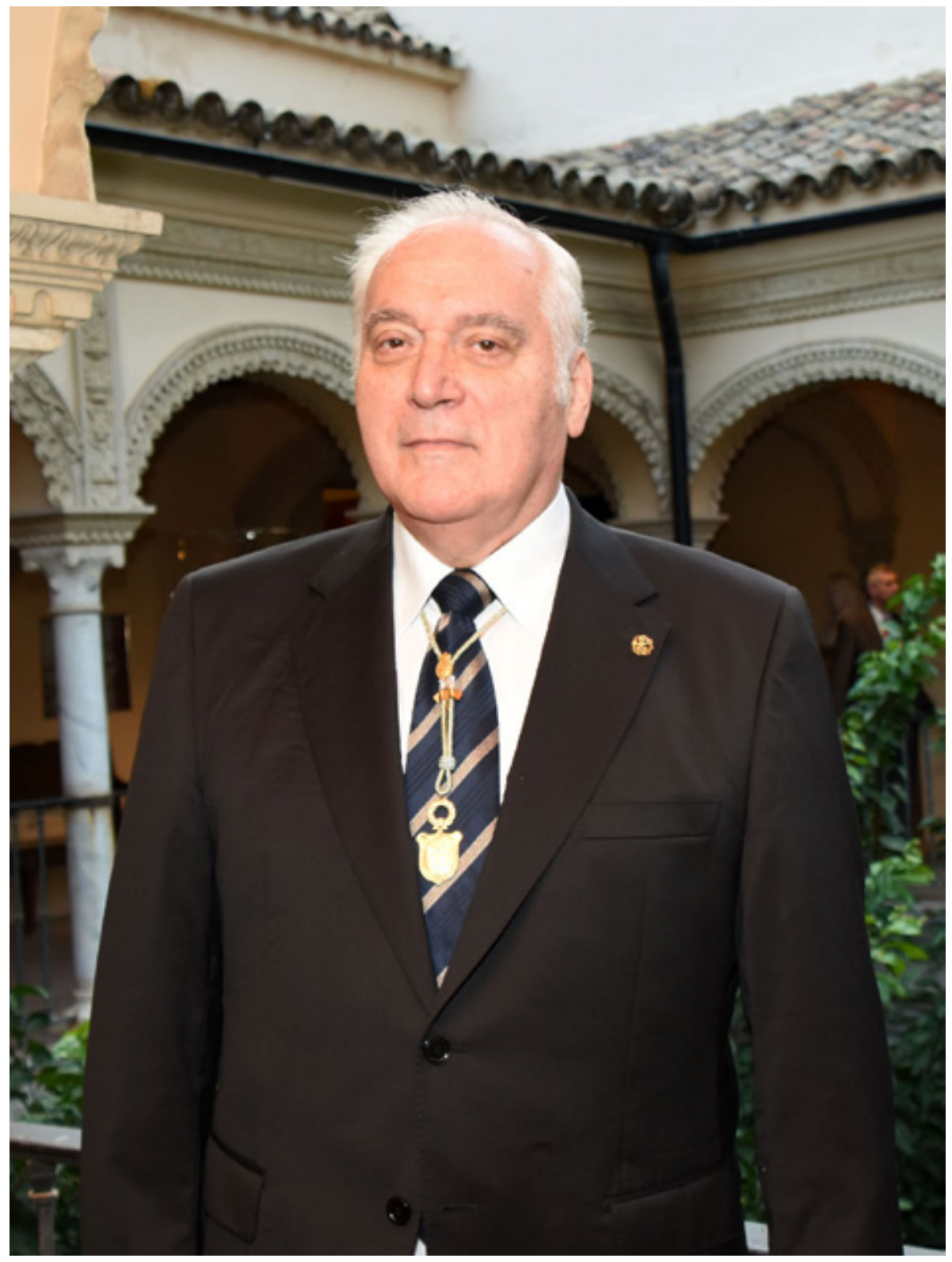




\title{
PRÓLOGO
}

\author{
EMilio Gómez PiÑol \\ Universidad de Sevilla. España
}

Agradezco cordialmente haber sido invitado a anteponer algunas consideraciones al homenaje que dedica el Departamento de Historia del Arte de la Universidad de Sevilla al Catedrático Profesor D. Juan Miguel González Gómez con motivo de su jubilación. Celebro que se haya decidido mantener la tradición de rememorar los largos años de servicios del Profesor jubilado, asumiendo las variadas circunstancias que jalonan el transcurso de la vida, con particular valoración de las nobles tareas que fundamentan las actividades de la institución universitaria.

Entiendo que el fácil acceso que los actuales recursos tecnológicos ofrecen para consultar el historial de los funcionarios pueda dispensarnos de la detallada enumeración, en nuestro caso, del pletórico currículum académico del Profesor González Gómez. Habida cuenta de las habituales implicaciones ante todo administrativas de tales documentos, baremos para evaluaciones, hemos preferido acercarnos a una escueta evocación de la trayectoria biográfica académica del Profesor homenajeado, en un intento de esbozar una semblanza de los hitos principales en el sentido primordial de las bases conceptuales y múltiples desarrollos de una amplia carrera universitaria abierta en el tiempo a numerosas variantes de la docencia universitaria, a variadas modalidades de la investigación y a múltiples actividades en la difusión cultural.

Espero cumplir el habitual exordio apropiado a la semblanza del Profesor González Gómez haciendo hincapié en la finalización de los cursos de su Licenciatura y la inmediata elaboración de la llamada Tesina. Por entonces estas actividades y estudios se desarrollaban en la Facultad de Filosofía y Letras. Los años de preparación de su primer trabajo de investigación van desde 1974 a 1978. Trabajo brillante, en la línea generalizada de una Facultad de Letras que ya había reunido un cuerpo docente de gran calidad que, según se ha publicado en nuestros días en el conjunto universitario nacional, en las principales ciudades afortunadamente se habían restañado buena parte de los daños de la Guerra Civil y era perceptible una creciente calidad en la dinámica de un sistema educativo que en términos generales funcionaba. 
La Tesis de Licenciatura, dirigida por D. José Hernández Díaz, se titulaba: El monasterio de Santa Clara de Moguer. Estudio histórico-artístico, leída en la Facultad de Filosofía y Letras en 1974, obtuvo el Premio Ciudad de Moguer (1975) y fue publicada por el Instituto de Estudios Onubenses "Padre Marchena", en Sevilla, 1978. La elaboración para la Tesina de un trabajo histórico-artístico pleno de múltiples aspectos históricos, sociales, eclesiásticos, y de riquísimo patrimonio estético en obras de diversos géneros plásticos dejó huella perdurable en su autor. Lo mismo cabría decir del magisterio del Director del trabajo, a quien el Profesor González Gómez siempre profesó una admiración explícitamente confesada y con trascendencia inmediata en los estilos oratorios y literarios que pronto habría de asimilar y desarrollar en su carrera docente. Podría afirmarse que en los años setenta la Facultad de Letras hispalense, sin necesidad de llamativos artificios burocráticos, desde la propia y natural relación de los remotos orígenes inspiradores de las Universidades: enseñar y aprender, se fomentaron grupos de profesores y alumnos que constituían lo que en las universidades más ilustres del ámbito europeo se denominaban tutorías; cuando circulaban sin interferencias extrañas las relaciones entre maestros y discípulos.

El cuantioso currículum de González Gómez desarrolla sus principales direcciones de actividad basándose en la gestación y culminación de la ya citada Tesina. La dualidad Sevilla-Huelva, o a la inversa, se convertirá en marco de acción permanente con novedades al avanzar el tiempo e incluirse nuevos enfoques temáticos en cuestiones del Patrimonio Monumental, intervenciones en asesoramiento de restauración de obras de arte, catalogación de obras monumentales y artísticas de zonas de la Archidiócesis hispalense -actualmente localidades y monumentos onubenses-, y muy particular atención y tratamiento de aspectos de gran trascendencia histórico-artística en los lugares colombinos. Académico numerario de la sevillana de Bellas Artes de Santa Isabel de Hungría, lleva más de veinte años en dicha institución, de los cuales nueve de Vicepresidente en la actual Junta de Gobierno.

De todo este ingente campo de acción pueden encontrarse en el currículum obras, artículos, conferencias, algunos trabajos de investigación -con Tesis Doctorales finales- que denotan la indiscutible profesionalidad: esto es capacidad y aplicación destacables en González Gómez. También su Tesis Doctoral (1982) titulada: Arquitectura en los siglos XVII y XVIII en la Tierra Llana de Huelva (Premio Extraordinario en 1986), asimismo bajo la dirección de D. José Hernández Díaz, supuso una importante incursión investigadora en un amplio espacio geográfico escasamente conocido.

Cuestión fundamental, permanente en toda la actividad del protagonista del currículum que glosamos, es la docente. Derivada de su propia formación universitaria, y tal vez con antecedentes vocacionales -González Gómez fue Maestro de Primera Enseñanza, y Profesor de Enseñanza General Básica por oposición-, en la Universidad tras la Tesina comenzó siendo Ayudante de clases 
prácticas. A partir de entonces recorrió todas las categorías, desde las tradicionales hasta las nuevas ajustadas a los cambios de planes de estudio. Profesor Titular, Catedrático, Cursos de Master, Doctorado y, frecuentemente, cursos destinados a grupos de estudiantes extranjeros matriculados en la Universidad.

En lo referente a los trabajos de investigación y sus variantes también las cifras son muy elevadas y en algunos casos se citarán más adelante en relación con premios y distinciones, sin olvidar que en los temas más novedosos o solicitados por instituciones culturales: Academia de Bellas Artes de Santa Isabel de Hungría, Maestranza de Caballería (Sevilla), instituciones onubenses, Congresos, etc., González Gómez mostró sus excelentes dotes oratorias y de clara estructura y exposición de los temas de su permanente atención: Escultura sevillana y andaluza, con su acreditada especialidad en época barroca, relación de las imágenes con el simbolismo iconográfico y su evolución y notorios episodios de la proyección cultural hispanoamericana.

Asimismo debe entresacarse de este denso panorama algunos trabajos de especial repercusión como promotor, coordinador de publicaciones de particular importancia o bien amplia colaboración en exposiciones y homenajes en las cuales el interesado contribuyó además con numerosas fichas catalográficas.

Particular acierto y repercusión tuvo la colaboración en actos específicos y en una espléndida publicación en dos tomos, la conmemoración del Centenario de la fundación en nuestra ciudad y su Facultad de Letras del Laboratorio de Arte (1907-2007). La promoción y gestión de tal acontecimiento de objetiva trascendencia universitaria y artística correspondió al que entonces estaba en su segundo periodo de Director del Departamento de Historia del Arte; el homenajeado en estas páginas: Prof. González Gómez. El para nosotros familiar nombre de "Laboratorio" relacionado con el Arte fue en realidad una ingeniosa y audaz idea del Prof. Francisco Murillo Herrera, el cual tuvo presente la semejanza de los Institutos Universitarios (presentes en otras Facultades de la Hispalense) pero era difícil conseguir el reconocimiento de que las actividades e investigaciones de las ciencias humanas $-\mathrm{H}^{\mathrm{a}}$ del Arte, ciertamente- necesitan además de libros, material técnico-fotográfico, para considerarse en cierto pie de intención metodológica análoga a la de las ciencias experimentales. De este certero razonamiento surgió el "Laboratorio de Arte".

No es posible en estas páginas repetir la nómina ilustre de los fundadores y numerosos profesores e investigadores adscritos a un impulso inolvidable de la investigación y transmisión de rigurosos conocimientos artísticos de Sevilla y su ámbito geográfico, y su proyección americana.

Volviendo a la mención de publicaciones relevantes relacionadas con la actividad de González Gómez, debe citarse su condición de Coordinador general -además de incluir un artículo sobre escultura astigitana- de Écija Barroca, Écija, 2011; también recientemente, junto al Dr. Jesús Rojas-Marcos González, y en su condición de Vicepresidente de la Real Academia sevillana de Santa Isabel de Hungría, 
elaboró un Catálogo de las esculturas de la Colección artística de Mariano Bellver. El inventario de toda la Colección contribuyó a justificar el subido interés ciudadano para que la citada colección -donada a la ciudad por sus propietarios-se conserve en un lugar apropiado para el mayor lucimiento de los numerosos y variados contenidos donados. Por último, en este apartado cabe citar la condición de Director de la Comisión Científica, a cargo de González Gómez, en la Exposición celebrada en la Catedral Hispalense, titulada: Misericordiae Vultus. El rostro de la Misericordia, cuyo catálogo se editó en Sevilla en 2016.

Llegados a este punto del resumen y breve glosa del amplísimo currículum de Juan Miguel González Gómez (280 páginas), quien esto escribe no quisiera dejar de mencionar algo importante de la plétora de méritos académicos aportados. Me parece oportuna la cita al menos de la estancia en el extranjero en universidades y centros culturales en tareas de investigación, coloquios y ponencias. Son las Universidades siguientes: Saint Etienne, Osnabrück, Creta, Fez, Amberes, Abdelmalek Essaadi (Tetuán), Museo Nazionale delle Arte e Tradizioni Popolari (Roma); y Centro de Estudios de imaginería Brasileira (Ceib), Natal, Río Grande del Norte (Brasil).

$\mathrm{Al}$ comienzo de estas páginas se indicó que algunas obras o actividades del personaje homenajeado serían citadas en el apartado específico del currículum titulado: "Distinciones y Premios". Llega el momento, pues, de proceder a esa enumeración que en alguna obra inicial ya ha sido comentada.

-El Ayuntamiento de Moguer otorgó (1978) el Premio Extraordinario "Ciudad de Moguer" a su Tesis de Licenciatura.

-La Real Sociedad Colombina Onubense concedió el Premio Extraordinario "Santa María de la Rábida" al libro: Escultura Mariana onubense. Historia. Arte. Iconografia, 1981.

-El Excelentísimo Ayuntamiento de Moguer concedió a Juan Miguel González la Medalla conmemorativa del Centenario de Juan Ramón Jiménez, como Comisario de la Exposición Antológica de pinturas y dibujos de Juan Ramón Jiménez (Casa Museo “Zenobia y Juan Ramón”), Moguer, 1982.

-Felicitación de la Comisión Provincial del Patrimonio Histórico Artístico de Huelva (Servicios prestados al Patrimonio cultural de Huelva), 1985.

-Medalla de Oro de "Los esplendores de Sevilla". Concesión del Consejo General de Hermandades y Cofradías de la Ciudad de Sevilla (1992).

-Giraldillo de bronce, Consejería de Educación y Ciencia de la Junta de Andalucía, (1996).

-Premio Alfonso X el Sabio, Asociación Alfonso X el Sabio, Sevilla, 2004.

-Premio Amigos de Écija. Defensa del Patrimonio de la ciudad, Excelentísimo Ayuntamiento de Écija, 2011.

-Agencia Andaluza del Conocimiento. Consejería de Economía, Innovación, Ciencia y Empleo. Dirección de Evaluación y Acreditación. Se extiende informe favorable para el nombramiento como Profesor Emérito de D. Juan Miguel González Gómez (5 de mayo de 2015). 
-Premio "Perejil de Plata" de la Fundación Zenobia y Juan Ramón Jiménez (28 de octubre de 2016).

-Medalla de Oro de la Universidad Internacional de Andalucía (UNIA), 2017.

-Premio Extraordinario "Pedro Alonso Niño", Excmo. Ayuntamiento de Moguer, a la monografía: Cristóbal Colón y Moguer en la historia del mundo, 2017.

No quisiera terminar estas consideraciones derivadas del cuantioso número de páginas donde en el positivo cómputo final se aprecia el indudable balance favorable de la profesionalidad y continuidad en los servicios prestados por el Profesor González Gómez a la institución universitaria y a la difusión cultural.

El acuerdo departamental de mantener la tradición universitaria de homenajear al Profesor jubilado aportando muestras del común trabajo de investigación, cobra especial sentido en estos tiempos de tensiones y desorientación en el mundo universitario.

En toda clase de ambientes se difunde la afirmación de la decadencia de la Universidad. Se omiten los matices y las excepciones, pero es preciso reconocer que las humanidades, a cuya área de conocimiento pertenece en lugar relevante la Historia del Arte, retrocede constantemente desplazada por la decadencia en las Universidades del propósito originario y esencial de búsqueda de la verdad del ser de las cosas y que es el fondo profundo del sentido, las aspiraciones y necesidades humanas. Se imponen como excluyentes los criterios del utilitarismo economicista para programar y apoyar las ciencias experimentales. Más claramente, con la intención de marginar todo lo ajeno a sus aplicaciones tecnológicas. Estas son acogidas con entusiasmo en sociedades relativistas, ajenas a la noción de consistencia y, por tanto, de verdad de los estratos más profundos de la realidad. Al parecer, nada importa abandonar el estudio de los hechos y circunstancias de la investigación rigurosa del pasado para tratar de comprenderlo y subsanar los errores y fundamentar el presente. En la vida histórica, y en las instituciones básicas - una de ellas, evidentemente la Universidad- se manipulan los hechos, se deterioran y diluyen las identidades y los protagonistas decisivos de la vetusta y gloriosa invención de la enseñanza en Occidente; el binomio maestros-discípulos se deconstruye y ahoga en la agobiante burocratización que a su gusto maneja el poder. Pese a todo, en las Universidades y Departamentos - el caso del histórico Departamento sevillano de Historia del Arte-, que acumula más de un siglo de actividad, cuenta con personas capaces de reformar y enderezar lo que sea necesario para revitalizar una labor que esencialmente pertenece a la parte espiritual de lo humano y se fundamenta en los valores de la convivencia y en las tradiciones universitarias, como ha sucedido en esta conmemoración que he tenido el honor de prologar. 